\title{
Investigation of the Advanced Failure of RC Structures Induced by Non-Structural Walls
}

\author{
Francis Deng Clement ${ }^{1,}$ a, Zhang Hong ${ }^{3, c}$, Yunning Cheng ${ }^{2, c}$ \\ ${ }^{1}$ Dept. of Architecture Southeast University Nanjing, China \\ ${ }^{3}$ Dept. of Architecture Southeast University Nanjing, China \\ ${ }^{2}$ Dept. of landscape Architecture Southeast University Nanjing, China \\ a francisdeng1@gmail.com; 'zhangh555@aliyuan.com 'ccyn999@126.com
}

Keywords: RC structure, impending enlargement, panel-type wall

Abstract: In this study, we investigate the effects of three types of non-structural reinforced concrete (RC) facade walls on the impending advanced failure of an $\mathrm{RC}$ frame. Linear and nonlinear static analyses are performed for RC frames with and without non-structural walls under three different column loss scenarios. Under an opening rate of 60\%, wing-type facade walls are more structurally sound than parapet- and panel-type walls. Panel-type walls can induce shear failure of the connected beam members and are the least preferable of the three types of walls considered in this work.

\section{Introduction}

The prevention or alleviation of advanced failure is a significant issue in the development of numerous structural design codes. Performance-based earthquake engineering tools are applied to a potential seismic safety problem: older non-ductile reinforced concrete frame structures [1].

The US General Services Administration (GSA) and the Department of Defense (DoD) have developed design and analysis strategies to evaluate the advanced failure of a structure. In this study, we investigate building performance during and after a disaster, particularly for reinforced concrete (RC) frames.

Non-destructive testing techniques provide a means to obtain important characteristics of historical structural masonry without [2].

The current design standards and building codes provide limited prescriptive or performance-based guidance on analysis or design to guard against progressive collapse [3]. Figure 1 shows one typical configuration of non-structural RC facade walls, which are defined herein as parapet-type walls. are commonly used, such as two sections coupled to the story columns, as shown in Figure 2.. Under column loss conditions, flexural failure is likely to occur in the wings without damaging the column section. A third type of wall, the panel-type wall, consists of exterior RC panels that are confined by the floor beams, as shown in Figure 3

\section{Types of Exterior Non-Structural Walls}

A. Modeling of the Building Frame and Exterior Walls We investigate the effects of the exterior walls for a 10-story, moment-resisting RC building with a 2-story basement. The floor plan of the considered structure is shown in Figure 4.

B. Modeling of the RC frame

A design yield strength, $\mathrm{fc}$, of $412,000 \mathrm{kN} / \mathrm{m}^{2}$ is used for the main reinforcements, and a design yield strength of $275,000 \mathrm{kN} / \mathrm{m}^{2}$ is used for the stirrups.. Catenary tensile action is not considered in this study.

C. Modeling of the non-structural walls

Comparable diagonal nonlinear links are used to determine the mechanical effects of the wing-type facade walls, as shown in Figure 5(b). However demand develop the concept to the stage where it is a viable and logical alternative to current force-based code approaches [4]. Finally, the panel-type 
walls are experimentally investigated using beam-column components that are positioned at the mid-span of spandrel beams, as shown in Figure 5(c). In order to enhance the performance of existing buildings to the present level of ductile design prescribed by present codes and find the retrofit or design a rehabilitation system [5]

\section{Progressive Collapse Analysis}

Pst $=2(\mathrm{DL}+0.25 \mathrm{LL})$

The GSA procedures recommend that physical inlets should be contiguous with the location where the column was removed. Herein, the GSA loading is denoted as Pst. Table 2(a)

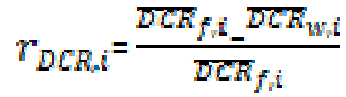

\section{Conclusions}

We investigate the effects of three typical types of exterior non-structural walls on the response of an $\mathrm{RC}$ building under column loss.

Table 1 Dimensions of RC member sections (cm)

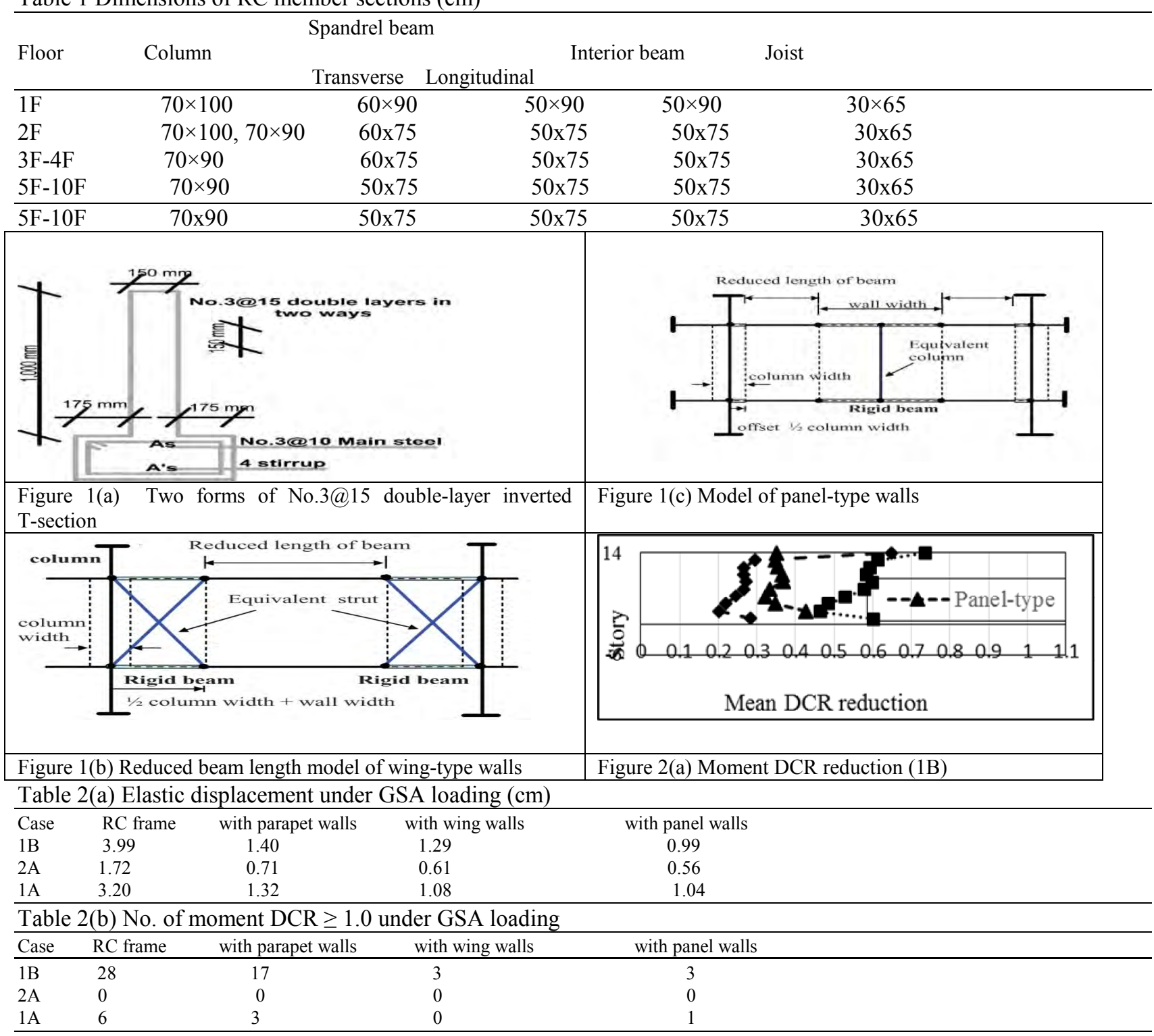




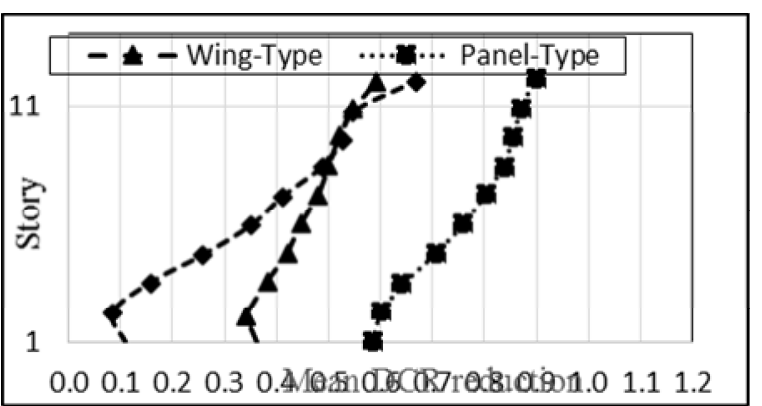

Figure 2(c) Moment DCR reduction (1A)

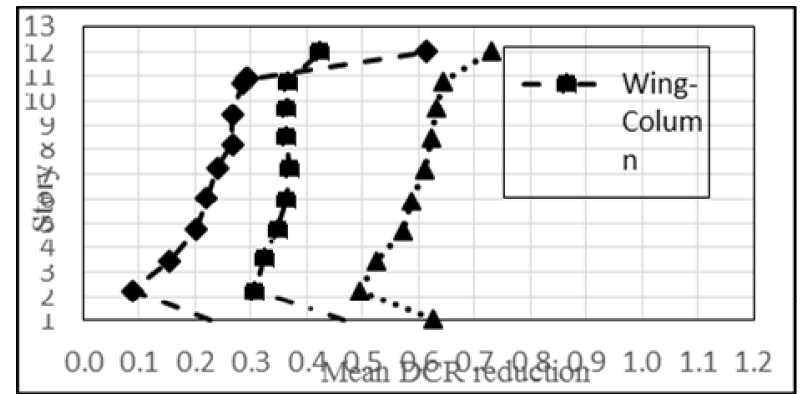

Figure 2(b) Moment DCR reduction (2A)

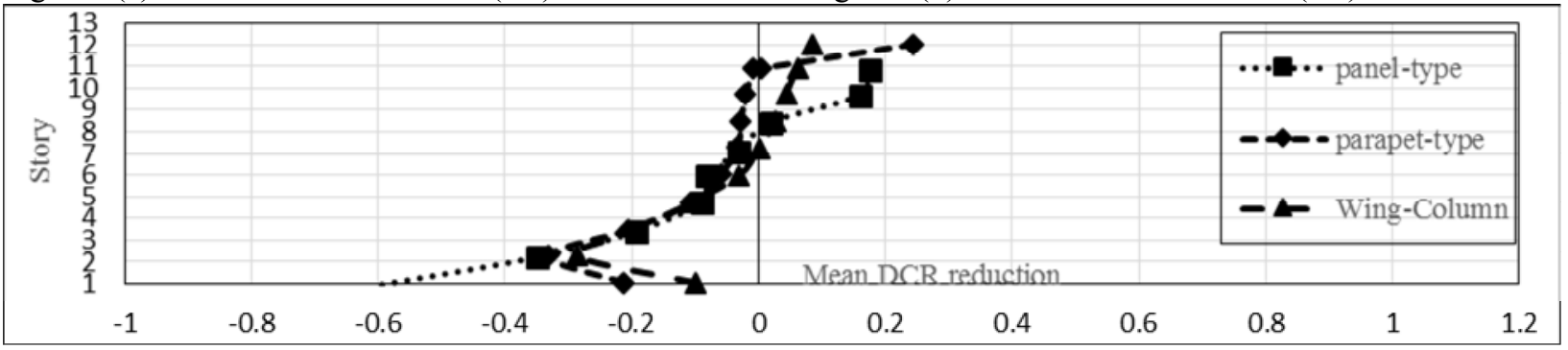

Figure 3(a) Shear DCR reduction (1B)

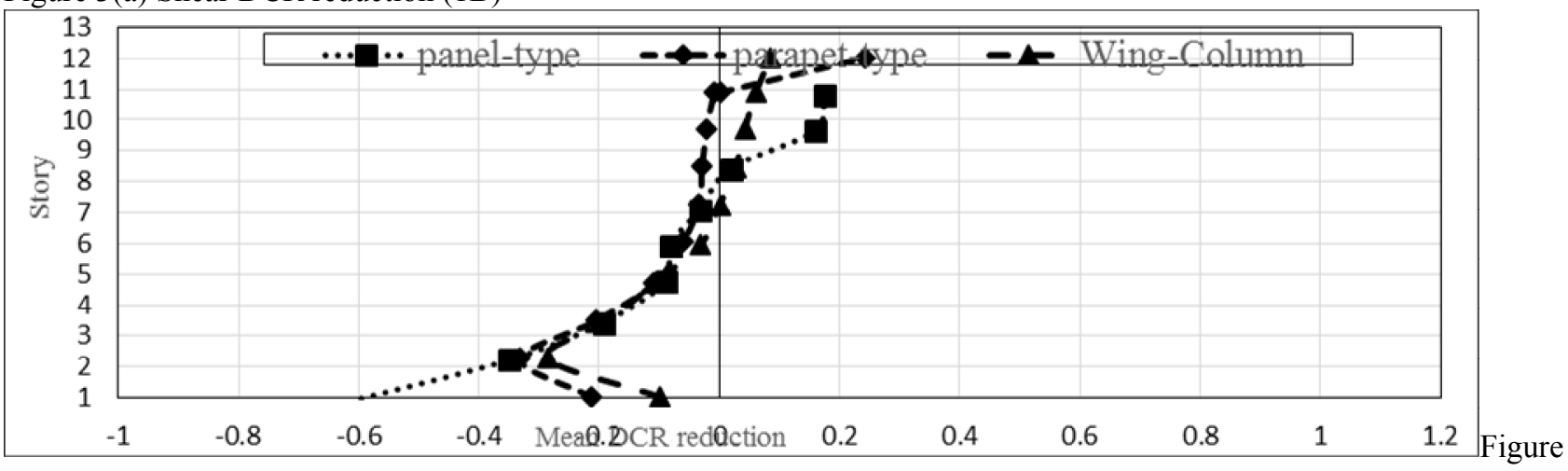

3(b) Shear DCR reduction (2A)

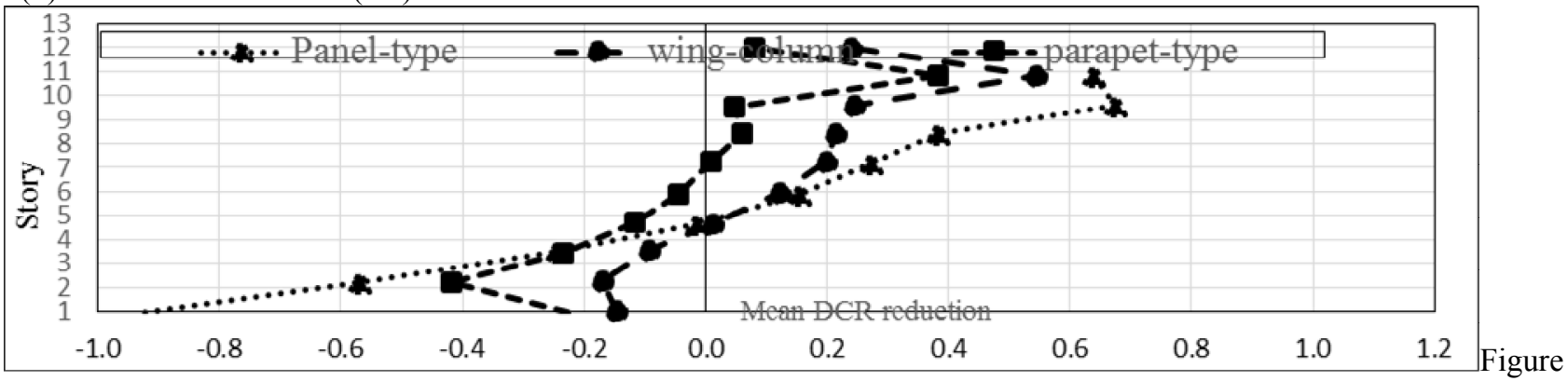

3(c) Shear DCR reduction

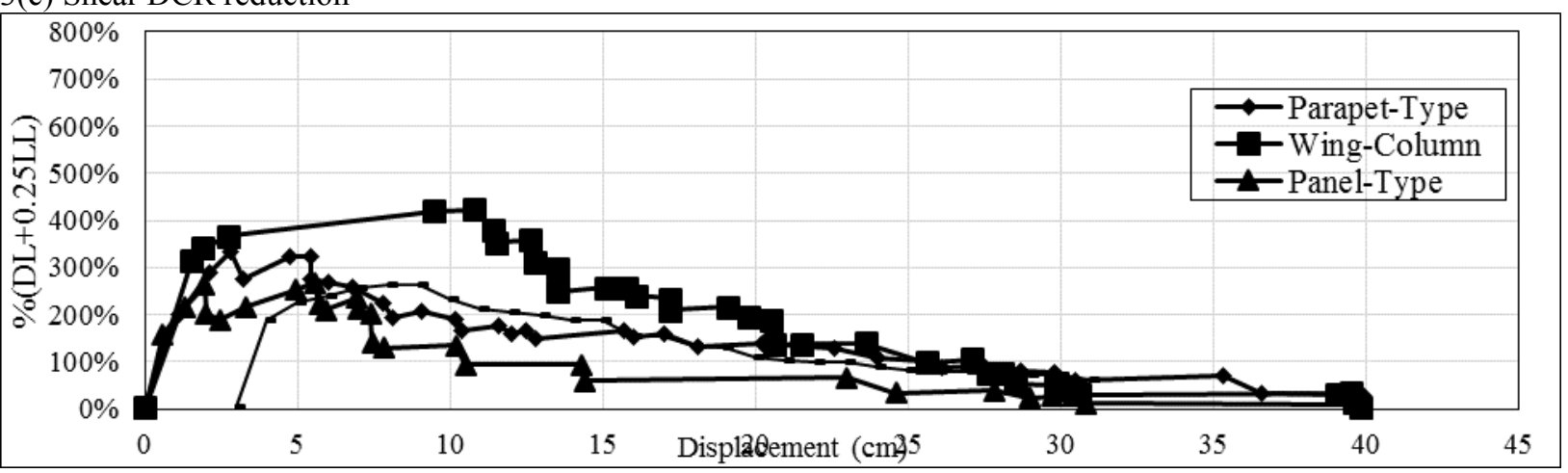

Figure 4(a) Push-down curve (1B) 


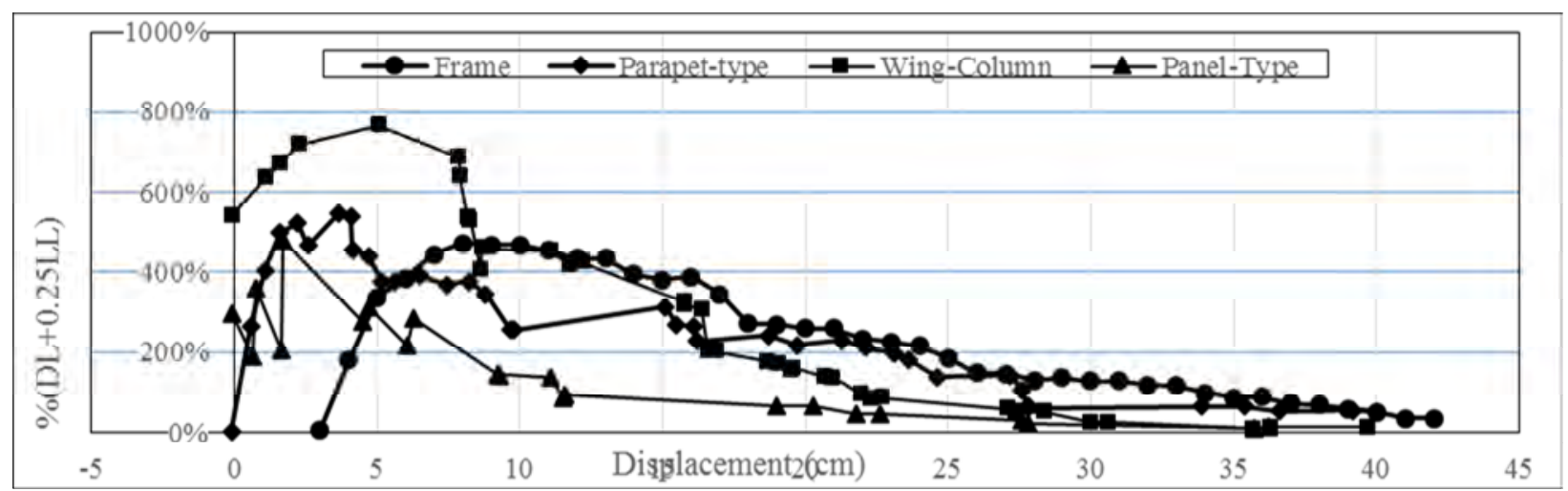

Figure 4(b) Push-down curve (2A)

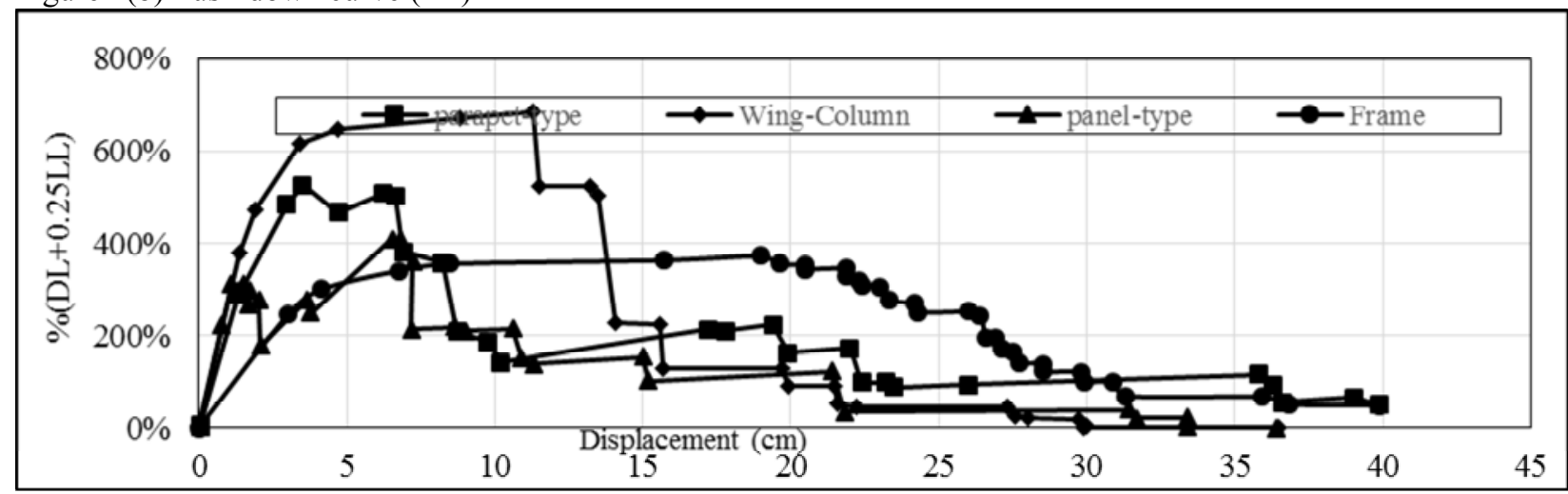

Figure 4(c) Push-down Curve (1A)

\section{Bibliography}

[1] A. B. Liel, "Assessing the collapse risk of California's existing reinforced concrete frame structures: Metrics for seismic safety decisions.," Stanford University, Northern California's, $2008 / 6$.

[2] E. C. Manning, "Enhancement of the tube-jack non-destructive test method for historical structural masonry diagnosis," EC Manning - 2016, 2016/12/7.

[3] O. A. Mohamed, "Progressive collapse of structures: annotated bibliography and comparison of codes and standards," Journal of Performance of Constructed Facilities, vol. 20, no. 4, pp. 418-425, 2006/11.

[4] G. C. M. K. MJN Priestley, "Direct displacement-based seismic design of structures," in 2007 NZSEE conference, New Zealand, 2007.

[5] A. C. N. R. I. K Rama Raju, "Seismic performance evaluation of existing RC buildings designed as per past codes of practice," Sadhana, vol. 37, no. 2, pp. 281-297, 2012/4/1. 